JURNAL ILMIAH TEKNOLOGI INFORMASI DAN KOMUNIKASI (JTIK) VOL 12, No.2, September 2021, pp. $48-57$

p-ISSN : 2087-0868 (media cetak)

e-ISSN : 2598-9707 (media online)

http://ejurnal.provisi.ac.id/index.php/JTIKP

\title{
PENERAPAN METODE RAPID APLICATION DEVELOPMENT UNTUK MENGEMBANGKAN SISTEM INFORMASI STOK BARANG MENGGUNAKAN LIVEWIRE LARAVEL
}

\author{
April Firman Daru1, Whisnumurti Adhiwibowo ${ }^{2}$, Helmy Dwi Anggara ${ }^{3}$ \\ ${ }^{1}$ Universitas Semarang \\ firman@usm.ac.id \\ ${ }^{2}$ Universitas Semarang \\ whisnu@usm.ac.id \\ ${ }^{3}$ Universitas Semarang \\ helmidwi0806@gmail.com
}

\section{ARTICLE INFO}

Article history:

Received : 28 - Agustus - 2021

Received in revised form : 7 - September - 2021

Accepted : 11 - Oktober - 2021

Available online : 16 - Oktober - 2021

\begin{abstract}
Inventory information system in $C V$. Elizabeth Parfumindo still uses manual steps such as making stock cards in excel, and to produce item reports, they still have to recap the item data one by one. With the number of data items that reach hundreds, it makes it difficult for the Warehouse Admin in the process of making weekly reports and monthly reports. Therefore, research was conducted to develop an information system for goods. The development of this information system uses the Laravel Framework with the MVC (Model, View, Controller) method and utilizes Livewire to build a User Interface so that it can easily create dynamic interfaces. In making the system, the method of data collection is done by means of observation, interviews and literature study. The steps taken in this case are system requirements analysis, system design and system testing. The system development method used is Rapid Application Development (RAD). For the design using the Unified Modeling Language (UML). The purpose of developing this goods information system is to facilitate the warehouse admin in the process of inputting and reporting.
\end{abstract}

Keywords : Stock Information System, Livewire Laravel, $R A D$

\begin{abstract}
Abstrak
Sistem informasi stok barang di CV. Elizabeth Parfumindo masih menggunakan tahapan manual seperti membuat kartu stok di excel, dan untuk menghasilkan laporan barang masih harus merekap data barang satu persatu. Dengan jumlah data barang yang mencapai ratusan menyulitkan admin gudang dalam proses pembuatan laporan mingguan dan laporan bulanan. Maka dari itu dilakukan penelitian untuk mengembangkan sistem informasi barang. Pengembangan Sistem informasi barang ini menggunakan Framework Laravel dengan metode MVC (Model,View, Controller) dan memanfaatkan Livewire untuk membangun User Interface sehingga dapat membuat tampilan antar
\end{abstract}


muka dinamis dengan mudah. Dalam pembuatan Sistem, metode pengumpulan data dilakukan dengan cara observasi, interview dan studi pustaka. Langkah-langkah yang dilakukan dalam hal ini adalah analisis kebutuhan Sistem, perancangan Sistem dan pengujian Sistem. Metode pengembangan Sistem yang digunakan yaitu Rapid Application Development (RAD). Untuk perancangannya menggunkana Unified Modelling Language (UML). Tujuan pengembangan Sistem informasi barang ini adalah untuk memudahkan admin gudang dalam proses penginputan dan pelaporan.

Kata Kunci : Sistem Informasi Stok Barang, Livewire Laravel, RAD

\section{PENDAHULUAN}

Perkembangan Sistem informasi berbasis komputer memberikan dampak teknologi yang penting bagi perusahaan termasuk diantaranya pengelolaan berbagai macam laporan dan stok barang. Proses barang masuk dan barang keluar yang makin mudah dan cepat memberikan kemudahan kepada pengguna sistem. Data yang disimpan dalam sistem informasi juga bisa dengan mudah kita olah tanpa harus merekap transaksi seacara manual, selain itu selisih barang dapat tertangani lebih cepat dan lebih akurat.

CV Elizabeth parfumindo adalah perusahaan yang bergerak di bidang minyak wangi (parfum). Di sektor gudang untuk pendataan stok barang masih menggunakan proses manual seperti membuat kartu stok untuk masing-masing barang di Microsoft excel sehingga kurang terjadi banyak kesalahan dan rentan manipulasi. untuk proses laporan memakan banyak waktu karena harus merekap lagi dari masing kartu stok. Sektor gudang merupakan salah satu sektor penting dalam perusahaan. Alur barang masuk dan alur barang keluar merupakan proses yang penting. Salah satu masalah yang sering terjadi ketika adanya selisih barang antara kartu stock dan fisik barang tersebut.

Pada penelitian dengan judul Sistem Informasi Stok Gudang Pada Platinum Hotel Berbasis Web dijelaskan bahwa Dengan software sistem inventory PLATINUM HOTEL, proses pengolahan data inventory gudang dapat diselesaikan dengan cepat dan akurat, serta lebih baik dari siklus pengolahan sebelumnya yang dilakukan secara manual. (7). Penerapan sistem informasi persediaan berfungsi untuk mencatat aset secara akurat berdasarkan data yang ada di buku rekening dan menggabungkan realitas fisik aset yang ada. Pemrosesan data yang terkomputerisasi akan mempercepat pemrosesan data dan menghemat waktu pemrosesan transaksi. (8). Sistem Informasi stok barang merupakan sistem yang berfungsi untuk mendata barang masuk dan keluar, Sistem ini memungkinkan user memberikan laporan yang tepat, akurat dan tepat sasaran tentang pemrosesan data produk dari gudang Anda ke kantor pusat Anda. (1). Kinerja pengelola gudang dapat disederhanakan dan dipercepat dengan menyesuaikan dengan perhitungan data persediaan. Selain itu, melalui pemanfaatan sistem informasi perusahaan dapat melihat persediaan barang dalam kurun waktu tertentu, serta informasi persediaan minimum dan maksimum, agar lebih tertata dalam proses transaksi persediaan sehingga mempersingkat waktu pengerjaan. Menjadi relatif lebih cepat, dan dapat meningkatkan kinerja pendaftaran gudang barang. (3). Perubahan dan penambahan sistem dari segi fungsi dan interface dapat membuat sistem terlihat lebih dinamis dan handal. Sistem informasi yang digunakan untuk pendataan komoditas dapat meningkatkan kinerja perusahaan dalam pencatatan dan pelaporan barang masuk dan keluar. (9). Pencatatan stok barang yang dilengkapi dengan sistem terkomputerisasi dapat meminimalisir kesalahan input dan penulisan yang sering terjadi pada proses yang sedang berjalan. tujuannya adalah agar user dapat memperoleh informasi persediaan dan memperoleh informasi data produk pada saat terjadi transaksi penjualan. (2).

Penerapan sistem informasi persediaan dapat mencatat aset secara akurat berdasarkan data yang ada di buku rekening dan menggabungkan realitas fisik aset yang ada. Pemrosesan data yang terkomputerisasi akan mempercepat pemrosesan data dan menghemat waktu pemrosesan transaksi (10). Berkat sistem komputerisasi inventory yang dioptimalkan, karyawan dipermudah dalam mengelola stok barang. (5).

Dari jurnal jurnal yang telah dipelajari di atas, dapat disimpulkan bahwa penerapan sistem informasi pada pendataan stok barang sangat dibutuhkan. Hal ini sangat penting, karena alur perputaran barang sangat rumit dan banyak, sehingga ketika terjadi perbedaan persediaan stok barang karena kesalahan atau salah masuk dapat segera diperbaiki daftar riwayat barang dengan barang.

Masalah lain yang sering muncul adalah pemimpin yang sibuk sehingga jarang berada ditempat kerja dan selalu membutuhkan laporan stok barang setiap saat. Sementara itu, proses yang berjalan belum otomatis (masih ditangani secara manual dengan Excel). Jadi, solusi yang bisa diberikan adalah Pengembangan sistem informasi Stok Barang,yang bisa diakses oleh pimpinan dan admin gudang secara online dan realtime.

Laravel Livewire merupakan framework php, memiliki fitur yang menarik yaitu real-time. Kecepatan pemrosesan input livewire berbeda dari kerangka kerja lain. Untuk memproses input, biasanya setelah memasukkan data, frame lain akan memuat ulang browser untuk menghapus data sebelumnya. Dan 
livewire dapat membersihkan data tanpa memuat ulang browser. Ini berarti sangat berguna untuk memasukkan data dalam jumlah besar dan menghemat waktu.

Adapun keunggulan livewire laravel yaitu mempunyai fitur realtime untuk mempercepat proses penginputan dan bisa diakses beberapa user dengan role yang berbeda (2).

Beradasarkan permasalahan tersebut diatas dibutuhkan sistem informasi barang online yang mengimplementaskan metode MVC dan menggunakan livewire laravel. Adapun keunggulan livewire lavavel yaitu mempunyai fitur realtime untuk mempercepat proses penginputan dan bisa diakses beberapa user dengan role yang berbeda.

Tujuan pembuatan sistem informasi barang ini adalah mempermudah pekerjaan admin gudang dalam mendata barang, penginputan barang, dan membuat laporan yang dapat diakses oleh pimpinan. Sistem informasi stok barang ini bisa di akses secara online, sehingga pimpinan bisa mengetahui laporan barang secara fleksibel dan realtime.

\section{METODE PENELITIAN}

Metode penelitian yang digunakan adalah metode penelitian kualitatif, dikarenakan dilakukan observasi atau studi lapangan dengan melihat secara langsung proses persediaan barang yang terjadi pada CV. Elizabeth Parfumindo. Model pengembangan sistem yang digunakan adalah Metode Rapid Application Development (RAD) terdiri dari fase-fase Bussiness Modeling, Data Modeling, Process Modeling, Application Generation serta Testing dan Turnover.

Rapid Application Development (RAD) adalah metode pengembangan perangkat lunak yang menggunakan kombinasi model prototype dan model iteratif. Prototype adalah model yang secara fungsional setara dengan komponen produk.

Dalam model RAD (Rapid Application Development), modul fungsional dikembangkan secara paralel sebagai prototipe dan diintegrasikan untuk membuat produk yang lengkap serta mempercepat pengiriman produk. Karena tidak ada perincian perencanaan yang terperinci, mudah untuk mengubahnya saat pengembangan sistem berlangsung.

Model RAD mendistribusikan fase analisis, desain, manufaktur, dan pengujian dalam serangkaian siklus pengembangan jangka pendek dan singkat. (6).

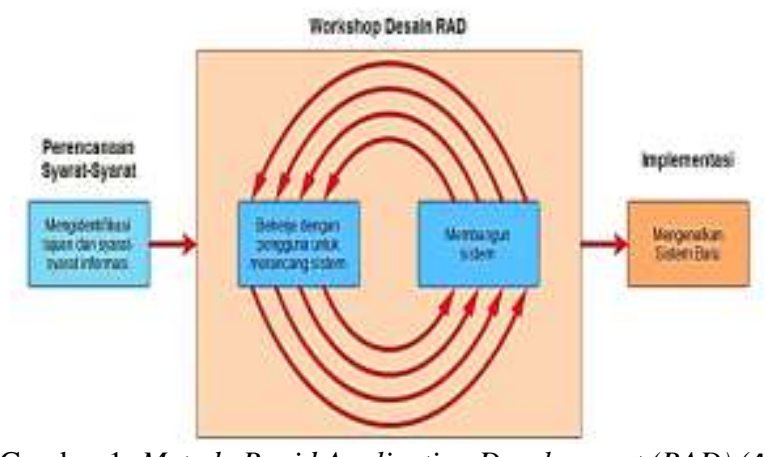

Gambar 1: Metode Rapid Application Development (RAD) (4)

Berikut adalah fase fase dar RAD:

\subsection{Business Modeling}

Tahap ini merupakan desain dasar dari distribusi informasi antara pengembangan produk informasi dan saluran komersial. Di fase pertama dimulai dengan berdiskusi dan menggali informasi dengan pihak $\mathrm{Cv}$. Elizabeth Parfum mengenai sistem informasi yang akan dibuat. Kebutuhan apa saja yang diperlukan.

\subsection{Data Modeling}

Tahap ini adalah untuk menganalisis informasi yang dikumpulkan dari tahap pemodelan bisnis. Semua kumpulan data telah diidentifikasi dan didefinisikan secara rinci untuk menemukan model bisnis yang tepat.

Di fase kedua setelah informasi terkumpul, dibuat rancangan sistem menggunakan mockup untuk presentasikan kembali dengan pihak CV. Elizabeth Parfumindo

JURNAL ILMIAH TEKNOLOGI INFORMASI DAN KOMUNIKASI (JTIK) VOL 12, No.2, September 2021, pp. 48 - 57 


\subsection{Process Modeling}

Tahap ini untuk menentukan arus informasi bisnis yang diperlukan untuk mencapai tujuan bisnis tertentu berdasarkan model bisnis. Tentukan perubahan atau peningkatan pada kumpulan objek data pada tahap ini. Memberikan deskripsi tentang proses menambah, menghapus, mengambil, atau memodifikasi objek data.

Tahap ketiga adalah mempresentasikan rancangan sistem ke pihak CV. Elizabeth Parfumindo untuk mengetahui apakah perancangan sistem yang sudah dibuat ada penambahan fitur atau sudah sesuai.

\subsection{Application Generation}

Tahap ini adalah Pengembangan system, pengkodean dilakukan dengan menggunakan Framework Laravel yang berfungsi untuk mengubah model proses dan data menjadi prototype yang actual.

Pada tahap ini dilakukan pembuatan sistem informasi stok barang. Setelah pembuatan Sistem selesai hasilnya dipresentasikan, Jika ada koreksi atau perubahan akan tetap masuk di fase ini sampai ada sistem sesuai kebutuhan.

\subsection{Testing and Turnover}

Tahap ini menguji seluruh sistem yang dibangun, dan semua komponen harus diuji secara menyeluruh dengan cakupan pengujian yang lengkap. Pengujian menyeluruh dapat mengurangi risiko cacat sistem.

Setelah mencapai kesepakatan dan tidak ada perubahan lagi, dilanjutkan dengan uji coba sistem secara menyeluruh sebelum benar-benar digunakan.

\section{Hasil Dan Pembahasan}

Hasil dan Pembahasan rancangan sistem informasi inventory sesuai dengan Rapid Application Development $(R A D)$.

\subsection{Bussiness Modeling}

Berdasarkan hasil diskusi dengan pihak perusahaan, penulis menyimpulkan analisa kebutuhan apa saja yang diminta oleh pihak perusahaan yaitu :

3.1.1 Kebutuhan Fungsional

Tabel 1. Analisa Kebutuhan Fungsional

\begin{tabular}{|c|l|l|}
\hline No & \multicolumn{1}{|c|}{ Kebutuhan Fungsional } & \multicolumn{1}{c|}{ Deskripsi } \\
\hline 1. & $\begin{array}{l}\text { Melakukan Pengelolaan data } \\
\text { Product }\end{array}$ & $\begin{array}{l}\text { Memasukan Data Product untuk disimpan dalam database } \\
\text { sistem }\end{array}$ \\
\hline 2. & $\begin{array}{l}\text { Melakukan pengelolaan data } \\
\text { Supplier }\end{array}$ & $\begin{array}{l}\text { Memasukan data Supplier untuk disimpan dalam database } \\
\text { sistem }\end{array}$ \\
\hline 3. & $\begin{array}{l}\text { Melakukan pengelolaan data } \\
\text { Custumer }\end{array}$ & $\begin{array}{l}\text { Memasukan data Custumer untuk disimpan dalam database } \\
\text { sistem }\end{array}$ \\
\hline 4. & $\begin{array}{l}\text { Melakukan Pengelolaan Barang } \\
\text { masuk }\end{array}$ & $\begin{array}{l}\text { Memasukan data barang masuk untuk di simpan dalam } \\
\text { database }\end{array}$ \\
\hline 5. & $\begin{array}{l}\text { Melakukan Pengelolaan Barang } \\
\text { keluar }\end{array}$ & Memasukan data barang keluar untuk disimpan dalam database \\
\hline 6. & Menggolah Laporan & Menampilkan data yang sudah diolah oleh sistem \\
\hline
\end{tabular}

\subsubsection{Analisa Kebutuhan User}

Berdasarkan analisa penulis, maka sistem informasi barang yang dibutuhkan oleh user adalah sebuah sistem informasi barang yang dapat memudahkan pihak gudang baik maupun pimpinan untuk mendapatkan informasi yang dibutuhkan Pengguna dalam sistem ini terdiri dari dua user, yang masing-masing mempunyai hak akses yang berbeda-beda diantaranya:

a. admin

User mempunyai hak akses sebagai pengelola data barang masuk dan keluar. Sebagai pengelola sistem informasi

b. pimpinan

pimpinan mempunyai hak akses kedalam sistem, pimpinan dapat masuk ke dalam menu laporan.

\subsection{Data Modeling}




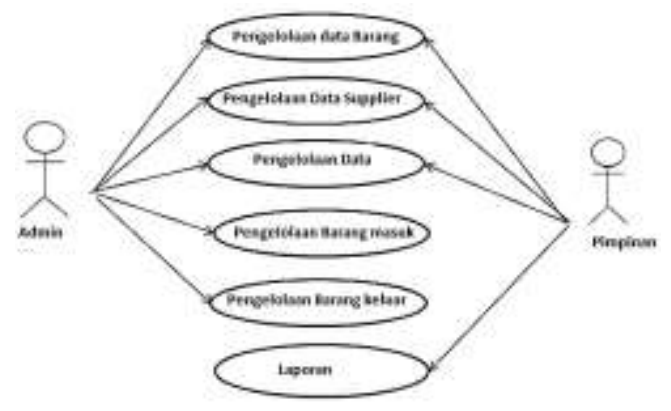

Gambar 2 : Use Case Diagram

3.2.2 Skenario Diagram

Skenario Use Case Pengelolaan data Product

Tabel 2 : Skenario Use case Product

\begin{tabular}{|l|l|r|l|}
\hline \multicolumn{2}{|c|}{ Aksi Aktor Alternatif 1 (Tambah Data Product ) } \\
\hline \multicolumn{2}{|c|}{ Aksi Sistem } \\
\hline 1 & Aktor masuk ke dalam sistem & 2 & Menampilkan form login \\
\hline 3 & $\begin{array}{l}\text { Login sebagai Admin atau } \\
\text { pimpinan }\end{array}$ & 4 & $\begin{array}{l}\text { Mengecek validasi semua data jika benar akan masuk } \\
\text { menu utama jika salah akan tetap di form login }\end{array}$ \\
\hline 5 & Masuk ke menu product & 6 & Sistem menampilkan menu product \\
\hline 7 & $\begin{array}{l}\text { Aktor mengisi semua data } \\
\text { product }\end{array}$ & 8 & $\begin{array}{l}\text { Sistem memvalidasi semua data product dan product } \\
\text { berhasil di tambahkan }\end{array}$ \\
\hline \multicolumn{3}{|c|}{ Alternatif 2 (Edit data Product) } \\
\hline 1 & $\begin{array}{l}\text { Pilih data product yang akan di } \\
\text { edit }\end{array}$ & 2 & Sistem Menampilkan data product yang dipilih \\
\hline 3 & $\begin{array}{l}\text { ubah data product yang mau di } \\
\text { edit dan tekan simpan }\end{array}$ & 4 & $\begin{array}{l}\text { Sistem menerima data setelah di edit dan product } \\
\text { berhasil di simpan }\end{array}$ \\
\hline \multicolumn{3}{|c|}{ Alternatif 3 (Hapus data) } \\
\hline 1 & $\begin{array}{l}\text { Pilih data product yang akan di } \\
\text { hapus }\end{array}$ & 2 & $\begin{array}{l}\text { Sistem memunculkan notifikasi sebelum data ke } \\
\text { hapus }\end{array}$ \\
\hline 3 & $\begin{array}{l}\text { Klik tombol ok untuk } \\
\text { mengkonfirmasi penghapusan } \\
\text { product }\end{array}$ & 4 & Data product berhasil di hapus \\
\hline
\end{tabular}

Skenario Use Case Pengelolaan data barang masuk

Tabel 3 : Skenario Use Case Barang Masuk

\begin{tabular}{|l|l|r|l|}
\hline \multicolumn{2}{|c|}{ Aksi Aktor Alternatif 1 } & (Tambah Data barang masuk ) \\
\hline 1 & Aktor masuk ke dalam sistem & 2 & Menampilkan form login \\
\hline 3 & Login sebagai Admin & 4 & $\begin{array}{l}\text { Mengecek validasi semua data jika benar akan masuk } \\
\text { menu utama jika salah akan tetap di form login }\end{array}$ \\
\hline 5 & Masuk ke menu pembelian & 6 & Sistem menampilkan menu pembelian \\
\hline 7 & $\begin{array}{l}\text { Aktor mengisi semua data } \\
\text { pembelian }\end{array}$ & 8 & $\begin{array}{l}\text { Sistem memvalidasi semua data pembelian dan data } \\
\text { berhasil di tambahkan }\end{array}$ \\
\hline \multicolumn{3}{|c|}{ Alternatif 2 (Edit data Custumer) } \\
\hline 1 & Masuk ke menu daftar pembelian & 2 & Sistem Menampilkan form daftar pembelian \\
\hline & Pilih data yang akan di edit & $\begin{array}{l}\text { Sistem Menampilkan data pembelian yang dipilih } \\
\text { di edit dan tekan simpan man data }\end{array}$ & $\begin{array}{l}\text { Sistem menerima data setelah di edit dan data } \\
\text { berhasil di simpan }\end{array}$ \\
\hline
\end{tabular}

JURNAL ILMIAH TEKNOLOGI INFORMASI DAN KOMUNIKASI (JTIK) VOL 12, No.2, September 2021 , pp. 48 - 57 


\begin{tabular}{|c|l|c|l|}
\hline 1 & $\begin{array}{l}\text { Pilih data pembelian yang akan } \\
\text { di hapus }\end{array}$ & 2 & $\begin{array}{l}\text { Sistem memunculkan notifikasi sebelum data ke } \\
\text { hapus }\end{array}$ \\
\hline 3 & $\begin{array}{l}\text { Klik tombol ok untuk } \\
\text { mengkonfirmasi penghapusan } \\
\text { data pembelian }\end{array}$ & 4 & Data pembelian berhasil di hapus \\
\hline
\end{tabular}

Skenario Use Case pembuatan laporan penjualan

Tabel 4 : Skenario Use case laporan penjualan

\begin{tabular}{|c|l|r|l|}
\hline \multicolumn{2}{|c|}{ Aksi Aktor } & \multicolumn{2}{c|}{ Aksi Sistem } \\
\hline \multicolumn{3}{|c|}{ Alternatif 1 (menampilkan data laporan penjualan ) } \\
\hline 1 & Aktor masuk ke dalam sistem & 2 & Menampilkan form login \\
\hline 3 & Login sebagai Pimpinan & 4 & $\begin{array}{l}\text { Mengecek validasi semua data jika benar akan masuk } \\
\text { menu utama jika salah akan tetap di form login }\end{array}$ \\
\hline 5 & $\begin{array}{l}\text { Masuk ke menu Laporan } \\
\text { penjualan }\end{array}$ & 6 & Sistem menampilkan menu Laporan penjualan \\
\hline
\end{tabular}

\subsection{Process Modeling}

3.3.1 Perancangan Database

Tabel 5 : Tabel Users

\begin{tabular}{|c|l|c|c|}
\hline No. & Nama Field & Tipe Data & Keterangan \\
\hline 1 & Id & Int & Primary key \\
\hline 2 & Name & Varchar & \\
\hline 3 & Email & Varchar & \\
\hline 4 & password & Varchar & \\
\hline 5 & role & varchar & \\
\hline
\end{tabular}

Tabel 6 : Tabel Products

\begin{tabular}{|c|l|c|c|}
\hline No & \multicolumn{1}{|c|}{ Nama Field } & Tipe Data & Keterangan \\
\hline 1 & Id & Int & Primary key \\
\hline 2 & Kode_barang & Varchar & \\
\hline 3 & Kode_Kategori & Varchar & Foreign Key \\
\hline 4 & Nama_Barang & Varchar & \\
\hline
\end{tabular}

Tabel 7 : Tabel pembelians

\begin{tabular}{|l|l|c|c|}
\hline No. & Nama Field & Tipe Data & Keterangan \\
\hline 1 & Id & Int & Primary key \\
\hline 2 & Product_id & int & Foreign Key \\
\hline 3 & qty & int & \\
\hline
\end{tabular}

3.3.2 Perancangan tampilan Sistem

a. Tampilan Sistem Login

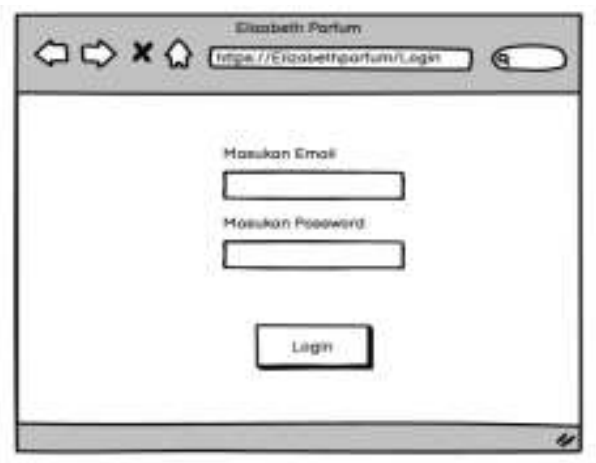

Gambar 3. Perancangan form login 
Gambar diatas adalah rancangan form login. Cukup memasukan email dan password setelah masuk sistim akan memvalidasi email dan password jika salah maka akan ada notif dan akan kembali ke form login

\section{b. Tampilan Menu Product}

Rancangan menu product digunakan jika kita ingin menambahkan data product dan melihat record data product serta dapat mengedit data product

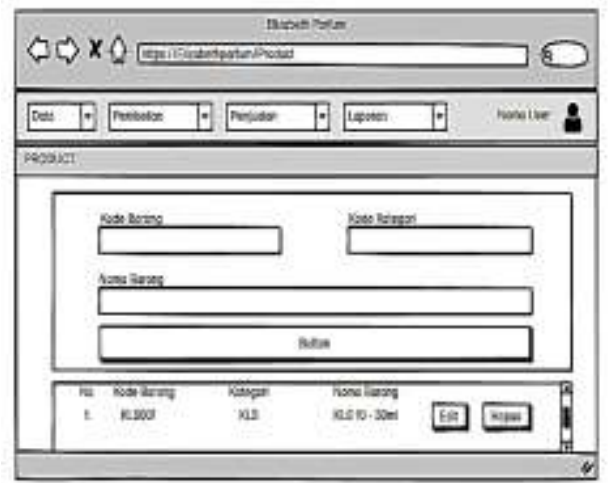

Gambar 4. Perancangan menu produk

c. Tampilan Menu Pembelian

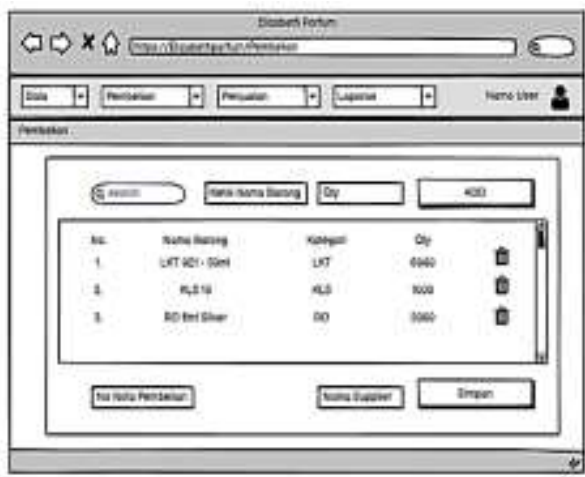

Gambar 5. Perancangan form pembelian

Perancangan form pembelian merupakan menu yang dapat diakses admin Gudang. Admin gudang dapat menginput pembelian yang di lengkapi dengan data supplier Setelah semua barang sudah di tambahkan masukan nama supplier dan no nota pembelian, selanjutnya di simpan.

\section{d. Menu Laporan}

Rancangan menu laporan dapat diakses user, dalam hal ini pimpinan. Data berasal dari record pembelian / penjualan yang di urutkan sesuai tanggal nota saat proses input. Melalui menu ini pimpinan dapat melihat semua hasil record penjualan dan pembelian.

JURNAL ILMIAH TEKNOLOGI INFORMASI DAN KOMUNIKASI (JTIK) VOL 12, No.2, September 2021 , pp. 48 - 57 
55

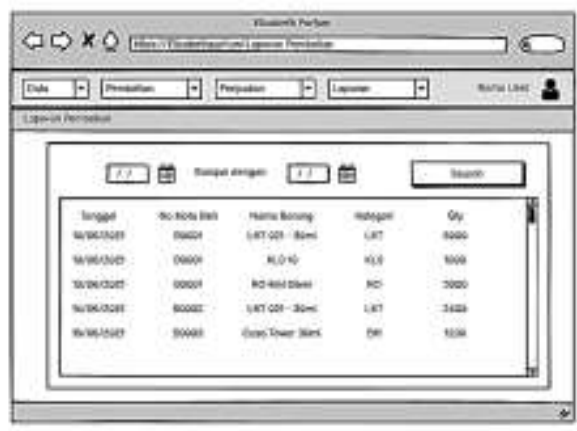

Gambar 6. Perancangan Laporan

\section{Application Generation}

Implementasi merupakan suatu tahapan dalam perancangan suatu perangkat lunak. Tahapan implementasi dilakukan setelah proses analisa dan perancangan selesai dilakukan. Pada tahap implementasi akan dibahas hal - hal yang berhubungan langsung dengan perangkat.

\subsection{Implementasi Antar Muka}

4.1.1 Tampilan Login

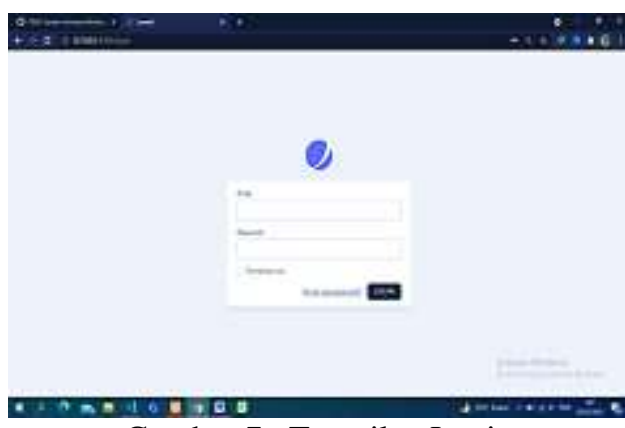

Gambar 7. Tampilan Login

Gambar 7 adalah form validasi untuk user sebelum memasuki menu utama / dashboard 4.1.2 Tampilan menu Product

Gambar 8 adalah Menu product, fungsinya untuk melihat data barang, mengisikan data barang, mengubah data barang maupun menghapus data barang.

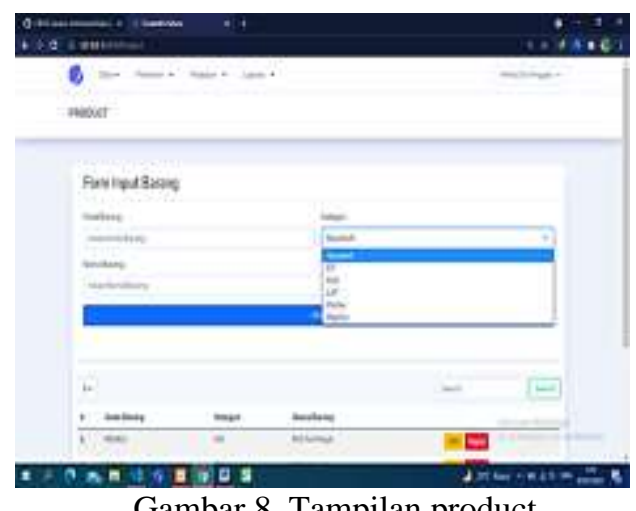

4.1.3 Tampilan menu Pembelian

Menu pembelian adalah menu yang berfungsi untuk menginput barang datang. Disini tabel yang di pakai yaitu tabel product, tabel supplier, tabel pembelian, tabel notabeli dan tabel notabeliproduct. 


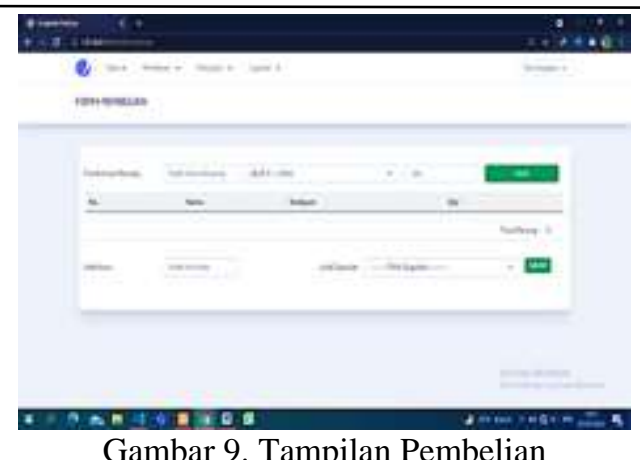

\subsubsection{Menu Laporan}

Menu laporan adalah menu yang bisa diakses pimpinan. Fungsinya adalah untuk mengcontrol segala jenis transaksi yang keluar maupun masuk. Tabel yang di pakai dalam menu ini yaitu tabel nota beli, tabel nota jual, tabel product

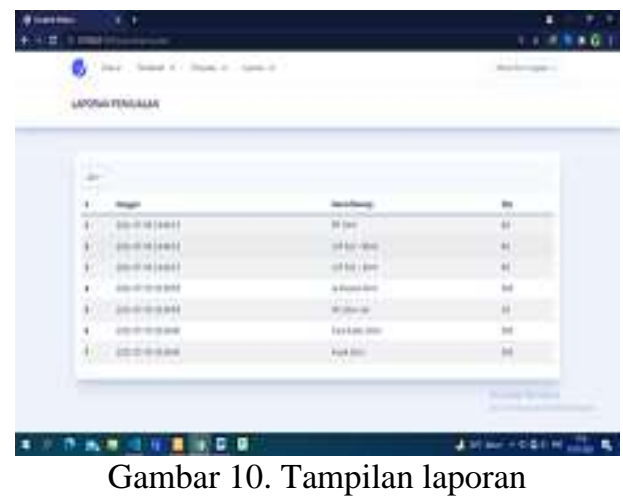

\section{Testing dan Turnover}

Pengujian ini dilakukan untuk mengeksekusi program, selanjutnya melakukan pemilihan menumenu dan konten yang tersedia dan melihat outputnya, apakah sesuai dengan yang diharapkan .

Tabel 8: Pengujian

\begin{tabular}{|c|l|c|}
\hline Modul Pengujian & \multicolumn{1}{|c|}{ Detail Pengujian } & Hasil \\
\hline Login Sistem & Verifikasi username dan password & Berhasil \\
\hline Menu Product & Melakukan create,update dan delete & Berhasil \\
\hline Menu Supplier & Melakukan create,update dan delete & Berhasil \\
\hline Menu Custumer & Melakukan create,update dan delete & Berhasil \\
\hline Menu Pembelian & Melakukan create,update dan hapus & Berhasil \\
\hline Menu Penjualan & Melakukan create,update dan hapus & Berhasil \\
\hline $\begin{array}{c}\text { Menu daftar } \\
\text { pembelian }\end{array}$ & $\begin{array}{l}\text { Menampilan daftar pembelian yang } \\
\text { telah diinput }\end{array}$ & Berhasil \\
\hline $\begin{array}{c}\text { Menu daftar } \\
\text { penjualan }\end{array}$ & $\begin{array}{l}\text { Menampilan daftar pembelian yang } \\
\text { telah diinput }\end{array}$ & berhasil \\
\hline $\begin{array}{c}\text { Menu stock } \\
\text { product }\end{array}$ & Menampilkan data stock product & Berhasil \\
\hline Menu laporan & Menampilkan data laporan & Berhasil \\
\hline Logout & Keluar dari program & Berhasil \\
\hline
\end{tabular}

\section{Kesimpulan}

Berdasarakan pengujian yang telah dilakukan, sistem informasi barang ini berfungsi untuk menginput pembelian dan penjualan. Sistem juga dapat menyimpan data product, custumer, supplier dan juga stock update serta dapat mencari data tersebut dengan cepat Sistem ini membagi 2 jenis laporan yaitu

JURNAL ILMIAH TEKNOLOGI INFORMASI DAN KOMUNIKASI (JTIK) VOL 12, No.2, September 2021 , pp. 48 - 57 
57

laporan penjualan dan pembelian yang dapat di akses setiap saat. Selain itu pemanfaatan Livewire Laravel mempermudah pembuatan interface sistem informasi menjadi dinamis tanpa menggunakan API (Application Programming Interface).

Sistem yang dirancang masih memiliki kekurangan yang dapat dikembangkan. Pada penelitian selanjutnya sistem dapat dikembangkan lagi dengan menambah fasilitas akuntansi dan status pengiriman agar lebih kompleks. Selain itu system belum memanfaatkan web service, sehingga kedepan bisa dilengkapi agar dapat dikembangan versi mobilenya namun dengan database yang sama

\section{Daftar Pustaka}

[1] Agusvianto, H. (2017). Sistem Informasi Inventori Gudang Untuk Mengontrol Persediaan Barang Pada Gudang Studi Kasus : PT.Alaisys Sidoarjo. JIEET (Journal Information Engineering and Educational Technology), 40-46.

[2] Ayu, F., Irfan, D., Ambiyar, Rahmad, M., \& Zulkifli, A. (2020). APLIKASI PERSEDIAAN BARANG ELEKTRONIK MENGGUNAKAN FRAMEWORK LARAVEL. Journal of Information Technology and Computer Science (INTECOMS), 207-217.

[3] Fauziah, S., \& Rahnawati. (2018). Penerapan Metode FIFO Pada Sistem Informasi Persediaan . Jurnal Teknik Komputer, 98-108.

[4] Kosasi, S., \& Yuliani, I. D. (2015). PENERAPAN RAPID APPLICATION DEVELOPMENT PADA SISTEM PENJUALAN SEPEDA ONLINE. Jurnal SIMETRIS, 27-36.

[5] Natusion, S., \& Frianti, R. A. (2019). Sistem Informasi Inventori Obat Berbasis Web di Rumah Sakit. Seminar Nasional APRIKOM (SEMNASTIK), 402- 409.

[6] Noertjahyana, A. (2002). STUDI ANALISIS RAPID APLICATION DEVELOPMENT SEBAGAI SALAH SATU ALTERNATIF METODE PENGEMBANGAN PERANGKAT LUNAK. JURNAL INFORMATIKA, 74-79.

[7] Ramadhani, T. S., Suryadi, S., \& Irmayani, D. (2018). SISTEM INFORMASI STOK GUDANG PADA PLATINUM HOTEL . Informatika : Jurnal Ilmiah AMIK Labuhan Batu, 35-40.

[8] Sari, A. O., \& Nuari, E. (2017). RANCANG BANGUN SISTEM INFORMASI PERSEDIAAN BARANG BERBASIS WEB DENGAN METODE FAST(FRAMEWORK FOR THE APPLICATIONS). Jurnal PILAR Nusa Mandiri Vol. 13, 261-266.

[9] Siregar, V. M., Sugara, H., \& Siregar, I. M. (2018). PERANCANGAN SISTEM INFORMASI PENDATAAN BARANG PADA PT. SERDANG HULU. Jurnal Computech \& Bisnis, 111-117.

[10] Tabrani, M., \& Pudjiarti, E. (2017). PENERAPAN METODE WATERFALL PADA SISTEM INFORMASI INVENTORI PT. PANGAN SEHAT SEJAHTERA. Jurnal Inkofar, 30-40. 